\title{
A Rare Syndrome Resembling Scleroderma: Huriez Syndrome
}

\author{
Nil Su Çelik ${ }^{a}$ Şirin Yaşar ${ }^{a}$ Sema Aytekin ${ }^{a}$ Pembegül Güneş ${ }^{b}$ \\ Departments of a Dermatology and b Pathology, Haydarpaşa Numune Training and Research Hospital, \\ Istanbul, Turkey
}

\section{Established Facts}

- Huriez syndrome is a very rare type of genodermatosis, in which acrosclerosis is the main characteristic clinical feature. Hypoplastic nails and the development of aggressive squamous cell carcinoma (SCC) arising in the scleroatrophic area are also distinctive features of the syndrome.

\section{Novel Insights}

- In Huriez syndrome, early diagnosis is critical for recognizing and preventing the development of SCC.

\section{Keywords}

Autosomal dominant inheritance $\cdot$ Keratoderma . Nail disorder · Sclerosis · Squamous cell carcinoma · Scleroderma-like findings

\begin{abstract}
Huriez syndrome, also referred to as "sclerotylosis," is a rare autosomal dominant genodermatosis characterized by the triad of congenital scleroatrophy of the distal extremities, palmoplantar keratoderma, and hypoplastic nails. The development of aggressive squamous cell carcinoma (SCC) arising in the scleroatrophic area is also a distinctive feature of the syndrome. Early diagnosis is important due to the early onset, mostly in the third to fourth decades of life, and aggressive progress of SCC, which occurs in around $15 \%$ of affected individuals. Our patient had palmoplantar keratoderma, scleroatrophy of the hands, and hypoplastic nails. Her mother and father had a second-degree blood
\end{abstract}

(c) 2017 S. Karger AG, Basel

E-Mail karger@karger.com www.karger.com/sad relation. Two of her siblings had similar complaints and findings. She showed no sign of actinic keratosis or SCC, and was called for regular follow-ups. With this case, we want to emphasize that Huriez syndrome is a rare genodermatosis, mimicking scleroderma-like acrosclerosis, and early diagnosis is critical for recognizing and preventing the development of SCC.

(c) 2017 S. Karger AG, Basel

\section{Introduction}

Huriez syndrome, also referred to as "sclerotylosis," is a rare autosomal dominant genodermatosis characterized by the triad of congenital scleroatrophy of the distal extremities, palmoplantar keratoderma (PPK), and hypoplastic nails $[1,2]$. It was first reported by $\mathrm{Hu}-$ riez et al. [1-3] in 1963 in 2 families from Northern France. The development of aggressive squamous cell 
Fig. 1. The patient presented with acrosclerosis, hardening of fingers, and hypoplastic nails.

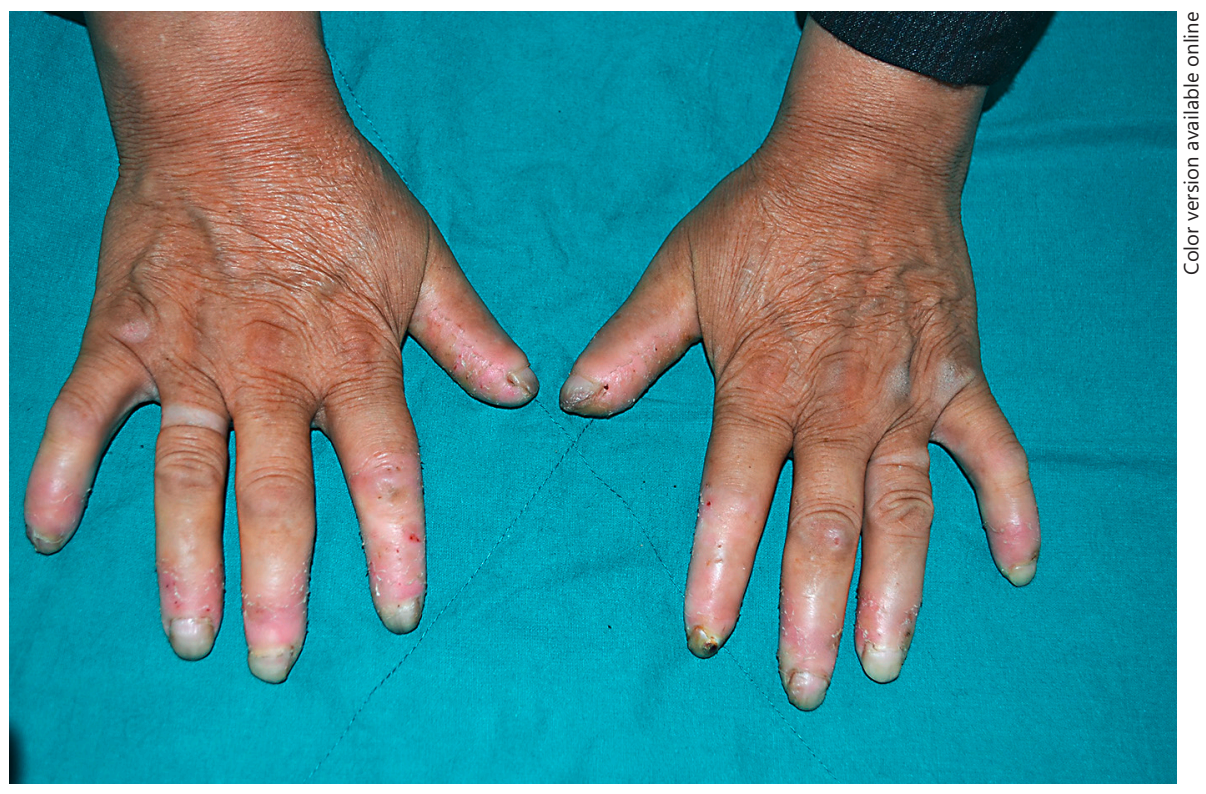

carcinoma (SCC) arising in the scleroatrophic area is a distinctive feature of the syndrome. Early diagnosis is important due to the early onset, mostly in the third to fourth decades of life, and aggressive progress of SCC, which occurs in around $15 \%$ of affected individuals [1-4].

\section{Case Report}

A 54-year-old woman presented to the outpatient department of our hospital with complaints of limitations of hand movements, thickening and stiffness of palms and soles, painful fissures and peeling of the skin of the hands and feet. She described the thickening and stiffness of her palms and soles as occurring since infancy. Her mother and father had a second-degree blood relation. Two of her siblings had similar complaints and findings. Dermatological examination revealed fingers with a shiny appearance and distal thinning of the fingers, as well as sclerotic changes with eroded fissures. The nails of the hands had a yellowish-brown discoloration, dystrophy, and distal thinning (Fig. 1, 2). Her soles, especially the areas that experience the most pressure when walking, had thick and stiff yellowish plaques with fissures (Fig. 3). Routine biochemical laboratory findings, hemogram, sedimentation, CRP, TSH, and fT4 were within normal limits. ANA, ENA, and anti-dsDNA were negative. A biopsy was performed on her sclerotic lesions. Histopathology showed compact hyperkeratosis, parakeratosis, hypergranulosis, irregular acanthosis, and mild papillomatosis (Fig. 4). Based on the clinical findings, histopathological results, and family history, we made the diagnosis of Huriez syndrome. Topical emollient containing $20 \%$ urea was used for treatment. She showed no sign of actinic keratosis or SCC, and the patient was called in for regular follow-ups.

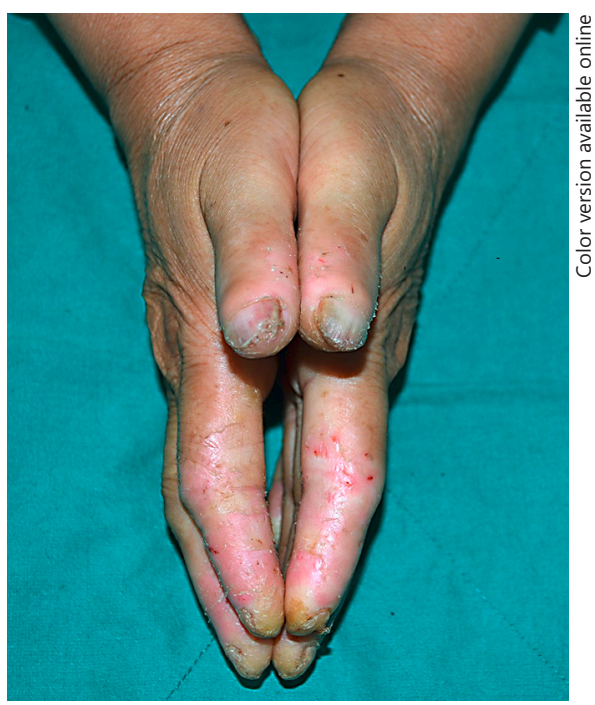

Fig. 2. Nail dystrophy and distal thinning. The "prayer sign" was observed.

\section{Discussion}

PPKs are a heterogeneous group of hereditary and acquired disorders with underlying gene defects. They are characterized by hyperkeratosis of palms and soles, with or without other ectodermal and systemic abnormalities. Huriez syndrome is a rare autosomal dominant variant of PPKs. A few nonfamilial, sporadic cases have also been 


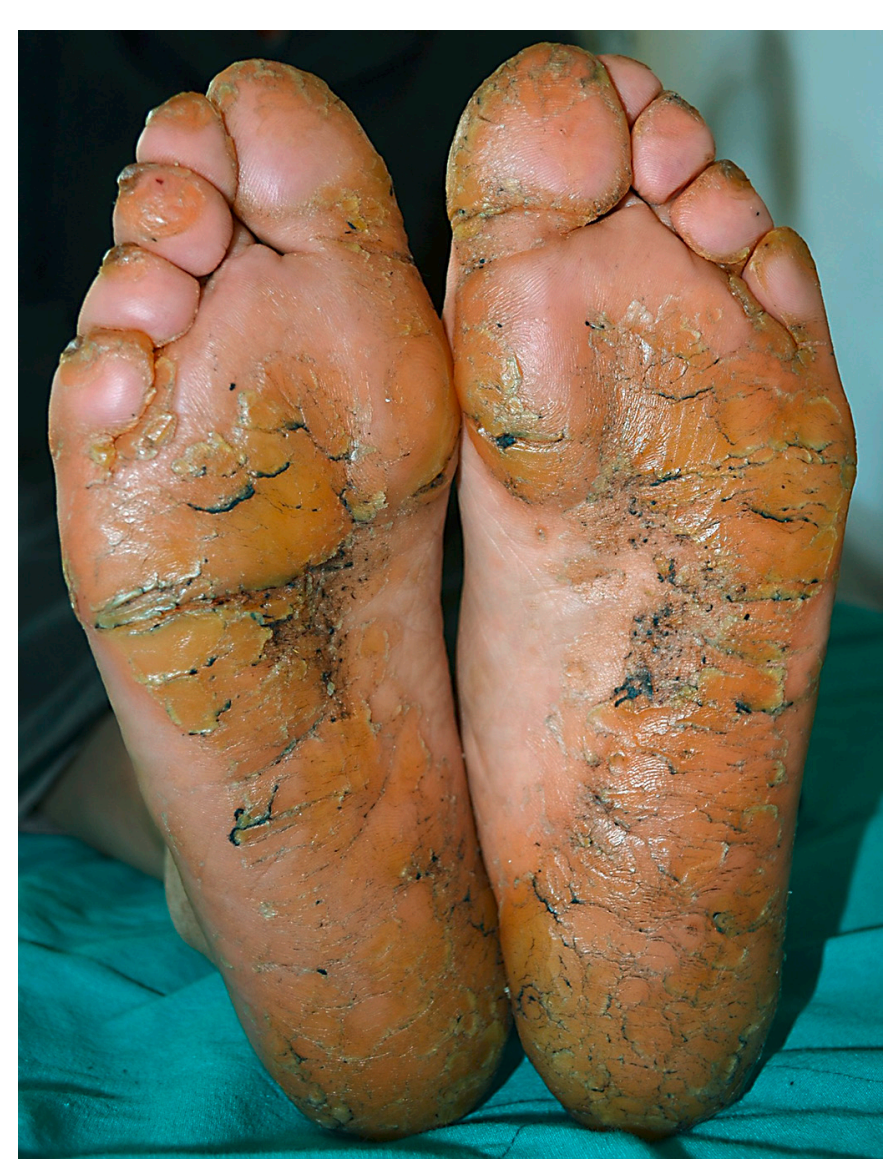

Fig. 3. Plantar thick keratoderma.

reported [2-6]. Since it was first reported in France, it has also been seen in India, Japan, Tunisia, Germany, and Italy [2-4].

There is individual variation in the clinical manifestations of Huriez syndrome. The importance of early diagnosis lies in the fact that SCC arises in around 15\% of affected patients. It is characterized by its early onset, more aggressive behavior and metastasis [1-4]. Affected individuals carry a $>100$-fold higher risk for the development of SCC [7]. The exact gene causing Huriez syndrome is still unknown. Deminatti et al. [8] found a probable linkage between Huriez syndrome and chromosome 4[4q2831]. Lee et al. [9] localized the position of the gene to be $4 \mathrm{q} 23 \mathrm{k}$. Watanabe et al. [4] found positive staining of p53 in atypical keratinocytes and suggested that p53 mutations may be responsible for the development of actinic keratosis and SCC in Huriez syndrome. The immunohistochemistry is characterized by a marked reduction in CD1a, Lag+, and S-100 epidermal Langerhans cells.

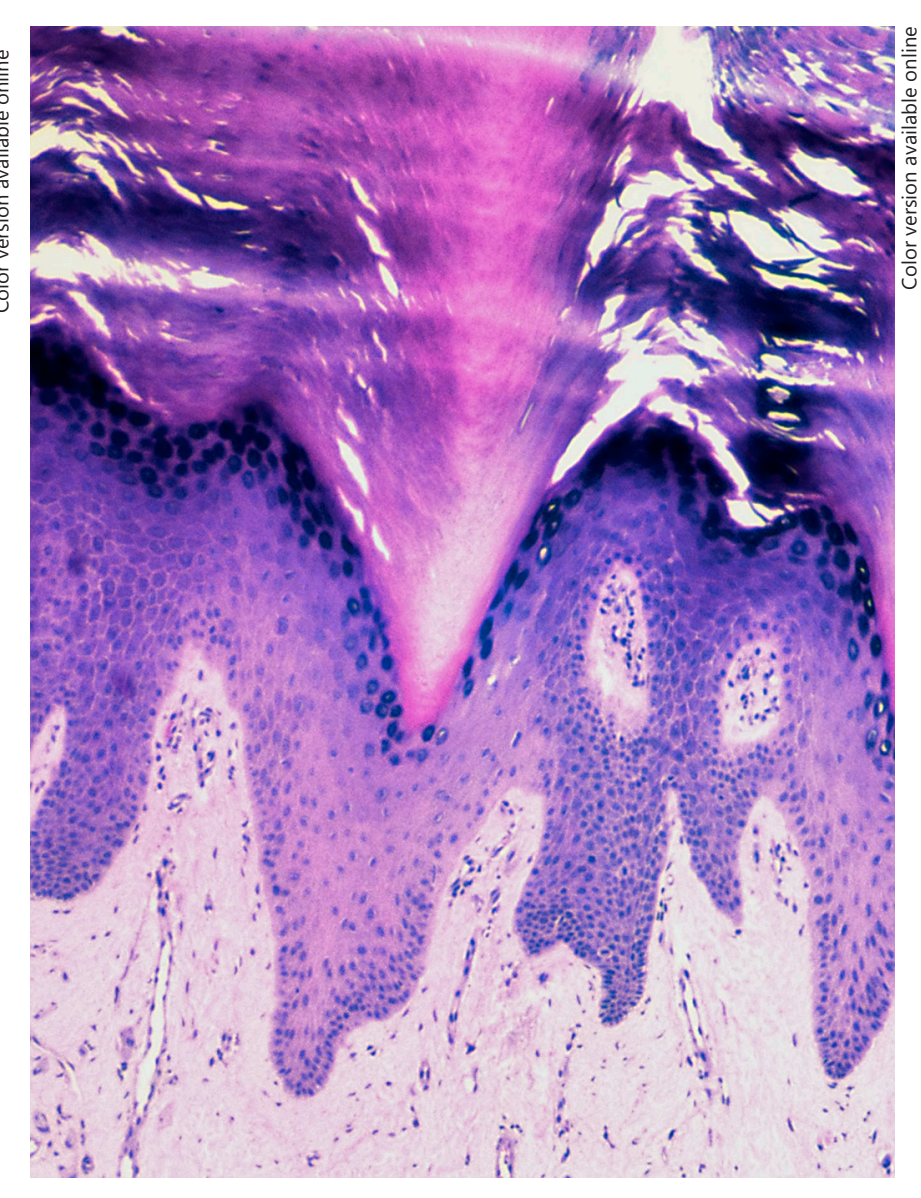

Fig. 4. Hypergranulosis, irregular acanthosis, and mild papillomatosis. HE. $\times 200$.

Because of the high cancer risk, close medical supervision and a multidisciplinary approach, with dermatologists, geneticists and plastic surgeons, are necessary. The treatment mainly addresses the symptoms; topical emollients, keratolytics, as well as topical and oral retinoids could be used.

Our patient had PPK, scleroatrophy of the hands, and hypoplastic nails. The histopathological findings showed compact hyperkeratosis, parakeratosis, hypergranulosis, irregular acanthosis, and mild papillomatosis. Based on the clinical findings and family history, we made a diagnosis of Huriez syndrome. The histopathological findings were nonspecific. Topical emollient containing $20 \%$ urea was used for treatment. The patient showed no sign of actinic keratosis or SCC, and she was called for regular follow-ups.

Differential diagnosis could be scleroderma, which has a late onset, less commonly with a family history, and also keratoderma is an unexpected feature. Another differen- 
tial diagnosis was dyskeratosis congenita, which is characterized by the triad of nail dystrophy, poikiloderma, and mucosal leukoplakia. Our patient did not have poikiloderma or leukoplakia.

With this case, we want to emphasize that Huriez syndrome is a rare type of genodermatosis, mimicking scleroderma-like acrosclerosis, and early diagnosis is critical for recognizing and preventing the development of SCC.

\section{Statement of Ethics}

The authors have no ethical conflicts to disclose. Written consent was obtained from the patient.

\section{Disclosure Statement}

The authors have no conflicts of interest to disclose.

\section{References}

1 Huriez C, Agache P, Bombart M, Souilliart F: Spinocellular epitheliomas in congenital cutaneous atrophy in 2 families with high cancer morbidity. Bull Soc Fr Dermatol Syphiligr 1963;70:24-28.

2 Sekar SC, Srinivas CR: Huriez syndrome. Indian J Dermatol Venereol Leprol 2008;74: 409-410.

$3 \mathrm{Al}$ Aboud K, Khachemoune A: Claude Huriez and his syndrome. Skinmed 2011;9:313-314.

4 Watanabe E, Takai T, Ichihashi M, Ueda M: A nonfamilial Japanese case of Huriez syndrome: P53 expression in squamous cell carcinoma. Dermatology 2003;207:82-84.
5 Vernole P, Terrinoni A, Didona B, De Laurenzi V, Rossi P, Melino G, et al: An SRY-negative XX male with Huriez syndrome. Clin Genet 2000;57:61-66.

6 Oyama M, Mitsuhashi Y, Saito H, Nagai E, Kondoh S: A case of Huriez syndrome (abstract, in Japanese). Jpn J Dermatol 2002;112:637.

7 Levi F, Franceschi S, Te VC, Randimbison L, La Vecchia C: Trends of skin cancer in the Canton of Vaud, 1976-92. Br J Cancer 1995; 72:1047-1053.
8 Deminatti M, Delmas-Marsalet $\mathrm{Y}$, Mennecier M, Marquet S, Agache P, Huriez C: Study of a probable linkage between a genodermatosis with an autosomal dominant transmission and the MNSs blood group system. Ann Genet 1968;11:217-224.

9 Lee, Young-Ae, et al: A gene for an autosomal dominant scleroatrophic syndrome predisposing to skin cancer (Huriez syndrome) maps to chromosome 4q23. Am J Hum Genet 2000;66:326-330. 